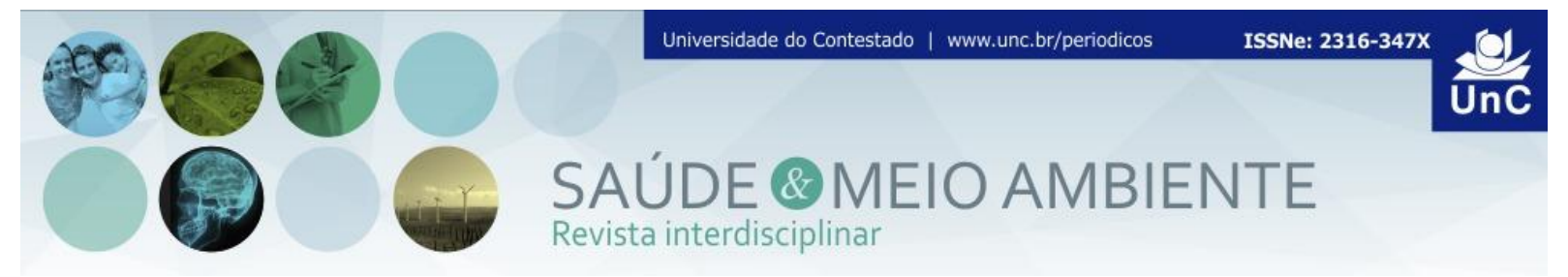

\title{
ABORDAGEM LABORATORIAL NO DIAGNÓSTICO DA RINITE ALÉRGICA E ASMA
}

\author{
Priscilla Fernanda Maeda ${ }^{1}$ \\ Flávia de Sousa Gehrke ${ }^{2}$ \\ Beatriz da Costa Aguiar Alves ${ }^{3}$ \\ Karen Spadari Ferreira ${ }^{4}$ \\ Thais Moura Gáscon ${ }^{5}$ \\ Fernando Luiz Affonso Fonseca ${ }^{6}$
}

\begin{abstract}
RESUMO
A rinite alérgica e a asma são patologias que apresentam uma alta prevalência mundial. Os fatores exatos que levam ao desenvolvimento destas patologias não estão totalmente esclarecidos, porém se observa em ambas o envolvimento de uma resposta alérgica com aumento de anticorpos $\mathrm{IgE}$ e mediadores inflamatórios. $\mathrm{O}$ diagnóstico para rinite alérgica e asma é baseado na história clínica do paciente e os exames laboratoriais requisitados a seguir ficam a critério do médico. O objetivo desta revisão foi realizar um levantamento dos mais recentes métodos de análises laboratoriais e suas aplicações para o auxílio no diagnóstico da rinite alérgia e da asma. A revisão foi realizada com base em artigos publicados a partir de 2000 em revistas nacionais, internacionais encontrados nos bancos de dados PubMed e Scielo. Os parâmetros de busca pesquisados no banco de dados PubMed foram: Allergic Rhinitis (\#1), Asthma (\#2), Treatment (\#3), Allergic Disease (\#4), Diagnosis (\#5). Neste trabalho foram demonstradas as vantagens e desvantagens dos principais exames laboratoriais: hemograma, VHS, determinação de leucotrienos, determinação de triptase, teste percutâneo, teste intradérmico, testes in vitro $\lg \mathrm{E}$ e testes de provocação. Os fatores que levam a escolha das metodologias devem considerar não apenas história do paciente, mas custo do método, disponibilidade de equipamento e/ou profissional habilitado para realizá-lo e possíveis interferentes do paciente. Os exames laboratoriais são fundamentais para o diagnóstico e acompanhamento da doença possibilitando a análise do tratamento e se está

\footnotetext{
${ }^{1}$ Curso de Farmácia e Bioquímica do Instituto de Ciências Químicas, Ambientais e Farmacêuticas Universidade Federal de São Paulo, (UNIFESP) Diadema (SP). Brasil. E-mail: pmaeda@uol.com.br ${ }^{2}$ Professora Titular - Universidade Paulista, São Paulo (SP), Pesquisadora Associada - FMABC, Santo André, Orientadora Programa de Pós Gradução IAMSPE, São Paulo (SP). Brasil. E-mail: flaviagehrke@hotmail.com

${ }^{3}$ Pesquisadora associada da Faculdade de Medicina do ABC, FMABC, Santo André, Brasil. E-mail: bcaalves@uol.com.br

${ }^{4}$ Professora do Curso de Farmácia e Bioquímica do Instituto de Ciências Químicas, Ambientais e Farmacêuticas - Universidade Federal de São Paulo, (UNIFESP) Diadema (SP). Brasil. E-mail: kferreira@hotmail.com

${ }^{5}$ Professora Auxiliar Faculdade de Medicina do ABC, FMABC, Santo André. SP. Brasil. E-mail: tmgascon@ig.com.br

${ }^{6}$ Doutor em Medicina pela USP. Professor do Curso de Farmácia e Bioquímica do Instituto de Ciências Químicas, Ambientais e Farmacêuticas - Universidade Federal de São Paulo, (UNIFESP) Diadema (SP). Brasil. E-mail: profferfonseca@gmail.com
} 
adequado ao paciente. As perspectivas para o futuro incluem busca por novos marcadores mais específicos e o desenvolvimento de novas tecnologias para os equipamentos diagnósticos.

Palavras-chave: Alergias. Diagnóstico. Rinite alérgica. Asma. Exames laboratoriais.

\title{
LABORATORIAL APPROACH IN THE DIAGNOSIS OF ALLERGIC RHINITIS AND ASTHMA
}

\begin{abstract}
Allergic rhinitis and asthma are diseases that have a high prevalence worldwide. The exact factors that lead to the development of these disorders are not fully understood, but it is observed in both the involvement of an allergic response with increased $\operatorname{lgE}$ antibodies and inflammatory mediators. The diagnosis for allergic rhinitis and asthma is based on the patient's clinical history and laboratory tests required to follow are the medical criteria. The objective of this review was to conduct a survey of the latest methods of laboratory analysis and its application to aid in the diagnosis of allergic rhinitis and asthma. The review was based on articles published since 2000 in national and international periodics found in the PubMed and Scielo database. The search parameters searched in the database PubMed were: Allergic Rhinitis (\# 1), Asthma (\# 2), Treatment (\# 3) Allergic Disease (\# 4) Diagnosis (\# 5). In this study we demonstrated the advantages and disadvantages of the main laboratory tests: blood count, erythrocyte sedimentation rate, determination of leukotrienes, determination of tryptase, percutaneous test, intradermal test, in vitro $\lg \mathrm{E}$ tests and challenge tests. The factors leading to the choice of methodologies should consider not only the patient's history, but the cost method, availability of equipment and / or a qualified professional to do it and possible interferences of the patient. Laboratory tests are essential for diagnosis and monitoring of disease allowing the analysis of the treatment and if it is appropriate to the patient. The perspective for the future includes the search for new more specific markers and the development of new technologies for diagnostic equipment.
\end{abstract}

Key-Word: Allergies. Diagnosis. Allergic rhinitis. Asthma. Laboratory tests.

\section{INTRODUÇÃO}

A rinite alérgica se caracteriza por ser uma inflamação das vias aéreas superiores, especificamente da mucosa. Esse processo inflamatório tem como sintomas: congestão, rinorréia, espirros coceira e prurido nasal (NG \& WANG, 2015). Quanto à epidemiologia, a Organização Mundial da Saúde (OMS), estima que cerca de $25 \%$ da população mundial sejam portadoras de rinite alérgica (PAHO, 2015). 
A asma é uma doença inflamatória crônica caracterizada por hiperresponsividade das vias aéreas inferiores e por limitação variável ao fluxo aéreo, reversível espontaneamente ou com tratamento, manifestando-se clinicamente por episódios recorrentes de sibilância, dispnéia, aperto no peito e tosse, particularmente à noite e pela manhã ao despertar. Um aspecto importante a se considerar é a inflamação crônica que pode alterar estruturalmente o epitélio alveolar de forma irreversível (MACEDO; ARAÚJO; DIAS, 2012). Segundo a OMS, cerca de 235 milhões de pessoas sofrem com a asma, que é a doença crônica mais comum entre as crianças (WHO, 2008). A epidemiologia desta doença se torna complexa pela falta de um marcador biológico ou fisiológico exclusivo, além da grande gama de sintomas relacionados à patologia.

No Brasil, a International Study of Asthma and Allergies in Childhood (ISAAC) estudou a prevalência destas patologias em três fases sucessivas e dependentes (SOLÉ; CAMELO-NUNES, 2008). Na primeira foi avaliada a prevalência e a gravidade, na segunda investigou os possíveis fatores etiológicos e a terceira foi uma repetição da fase I após um período mínimo de cinco anos. Os resultados obtidos mostraram que a presença da asma em crianças (6 a 7 anos) e adolescentes (13 a 14 anos) foi de: asma ativa 24,3\% e 19\%; asma grave 6,1\% e 4,7\%; e asma diagnosticada 10,3\% e 13,6\%; respectivamente. A média da prevalência da rinite para crianças e adolescentes na mesma faixa etária já citada foi: rinite ativa $25,7 \%$ e $29,6 \%$; rinoconjutivite $12,6 \%$ e $14,6 \%$; e rinite grave $17,1 \%$ e $17,4 \%$.

Uma das teorias que busca explicar a causa da asma é a hipótese da higiene. Os pesquisadores que a defendem, consideram que uma maior exposição das crianças a agentes infecciosos entre outros fatores reduz a possibilidade destas desenvolverem asma e doenças alérgicas (SOLÉ, 2003). Entretanto, Nunes (2011) reconhece que há alguns achados inconsistentes como o porquê da prevalência de doenças autoimunes (mediadas por linfócitos T CD4, Th1) aumentarem no mesmo intervalo de tempo que as doenças mediadas por linfócitos T CD4, Th2. O grupo de Casagrande et al., (2008) utilizando o modelo de questionário do ISAAC, considerando apenas a cidade de São Paulo, observaram a coexistência da alta prevalência da asma em condições precárias de higiene, o que de certa forma contraria a hipótese da higiene.

Vários pesquisadores consideram a rinite alérgica e a asma doenças relacionadas. Dentre os pacientes asmáticos $85 \%$ apresentam rinite alérgica, por outro lado entre os pacientes que possuem rinite alérgica cerca de $40 \%$ irão desenvolver asma (Nathan, 2009). Em ambas, há interação entre os alérgenos, imunoglobulina E ( $\lg E)$ e o papel primordial da inflamação. Atualmente, há cerca de 200 especificidades de alérgenos que podem ser dosados em laboratórios (HAMILTON et al., 2010). É sabido que a lgE desempenha papel central na resposta de hipersensibilidade imediata. Esta imunoglobulina foi identificada em 1967 e tem sido utilizada nos diagnósticos para confirmar sensibilização do paciente. Para que ocorra a síntese de IgE é preciso ativar a célula $B$, o que pode ocorrer ainda dentro do útero. Na primeira etapa há o contato do alérgeno com a imunoglobulina $\mathrm{M}(\lg \mathrm{M})$ de membrana célula B imatura, seguida pela expansão clonal e diferenciação desta célula. Na segunda etapa, chamada de troca recombinante de classe da cadeia 
pesada, há um rearranjo que termina na troca de classe do anticorpo (Ac). Ou seja, produção das outras classes de imunoglobulinas (lg) que apresentam a mesma especificidade antigênica. A síntese da $\lg E$ é induzida pela presença das interleucinas (IL) IL-4 e IL-13 e pela ligação do CD 40L da célula T. A IL-5 se destaca atuando na ativação dos linfócitos $B$ e promovendo diferenciação e maturação de eosinófilos (ZAVADNIAK; ROSÁRIO, 2005). As interações entre a IgE e os seus ligantes são mediadas pelos receptores de Fc presentes, os quais interagem com os receptores de alta afinidade FC€RI que estão presentes nos mastócitos, basófilos, células de Langherhans além de outras células do sistema imune. Na recorrência do contato o antígeno, o mastócito se ativa e ocorre a degranulação (CANONICA; COMPALATI, 2009). Em pacientes com algumas peculiaridades foram relatadas a presença deste receptor em outras células, por exemplo, nos monócitos de pacientes atópicos. Devido ao papel da lgE na fisiopatologia da asma alérgica e da rinite, a mesma tornou-se um alvo farmacológico indicado para os pacientes de asma grave de difícil controle em que os tratamentos convencionais não apresentam os efeitos desejados Farmacoterapia com IgE e Anti-IgE Terapia (CORDEIRO; SILVA 2008). O primeiro anti-IgE em uso clínico foi o omalizumabe um Ac que se liga a IgE livre (Ac IgG1 com uma pequena porcentagem de Ac murino). Este Ac é o responsável por se ligar especificamente a $\mathrm{lgE}$. Uma característica importante do omalizumabe é que ele aumenta a segurança na imunoterapia levantando a hipótese de uma futura associação entre essas duas terapias (SARINHO; CRUZ, 2006).

$\mathrm{Na}$ rinite alérgica observa-se a ativação das diversas células do sistema imune. Há indução da fosfolipase, que por sua vez, atua nos fosfolipídios de membrana acarretando no aumento de ácido araquidônico. Este ácido pode percorrer duas vias: a da enzima cicloxigenase ou da enzima lipoxigenase. A primeira resulta na formação de prostaglandinas que aumentam a permeabilidade vascular, prurido, agregação e ativação plaquetária. $\mathrm{Na}$ segunda via ocorre formação de leucotrienos. Estes têm ação similar a histamina promovendo vasodilatação, aumento da permeabilidade vascular, secreção glandular e estimulação das terminações nervosas. A fase tardia que ocorre de 4 a 12 horas após o contato com o alérgeno apresenta como uma das principais características a migração de eosinófilos, macrófagos e linfócitos entre outras células inflamatórias. Os eosinófilos participam diretamente do dano tissular e na liberação de mediadores como o fator estimulador de formação de colônias de granulócitos e macrófagos, leucotrienos, quimiocinas e citocinas (SOLÉ et al., 2006).

A asma é uma síndrome comum, crônica, heterogênea e não há um mecanismo único em seu desenvolvimento. Fenótipos de asma podem ser muito mais complexos e exigir um laboratório dedicado e centro especializado para caracterizar; como o uso de marcadores celulares ou bioquímicos na expectoração induzida ou em biópsias brônquicas. Estas características são utilizados principalmente em ambientes de testes clínicos e em pesquisas. Entretanto, nos últimos anos têm sido preconizado o manejo da asma individualizada e adaptado não só para a gravidade da doença, mas sobretudo às características fenotípicas do paciente (BOSTANTZOGLOU et al., 2015). Townley et al., (2011) ressaltam todos os efeitos diretamente relacionados entre a IL-13 e a asma. Há aumento na secreção de muco em que a IL-13 apresenta maior influência que a IL-4, inflamação da via 
respiratória, hiper-reatividade bronquial e fibrose dos tecidos. Pacientes foram separados em grupos considerando se eram fumantes ou não, se possuíam dermatite atópica, asma ou rinite, além do grupo controle. Foi observado que os grupos que possuíam atopia apresentavam níveis mais elevados de IL-13Ra do que o grupo controle. Este receptor inibiria a ação da IL-13. Desta forma demonstrou-se que IL-13 pode vir a ser utilizada como um marcador para as patologias atópicas (Hussein et al., 2010). Outras citocinas, dentre elas a família da IL-17, são capazes de promover também efeitos imunológicos. Dentre elas se destaca a IL-17E que induz respostas do tipo Th2. AIL-17A em conjunto com IL-17F agravam a resposta pulmonar inflamatória ao facilitarem o influxo de células inflamatórias e estão relacionadas ao remodelamento das vias respiratórias.

Em relação ao tratamento, há uma lista restrita de medicamentos para uso tanto de rinite quanto para asma e apenas na forma farmacêutica oral. O serviço público não possui locais especializados em asma para o número de pacientes existentes (HOLANDA, 2000). Outro problema são os recursos humanos, programas de capacitação deveriam estar disponíveis para que o diagnóstico correto, com mais frequência, fosse emitido (LEAL et al., 2011).

Considera-se ainda como potenciais determinantes das doenças alérgicas fatores ambientais como mudanças no estilo de vida, dieta e maior exposição à alérgenos. O objetivo desta revisão foi abordar as metodologias utilizadas para diagnóstico da rinite alérgica e da asma.

\section{METODOLOGIA}

A revisão foi realizada com base em artigos científicos publicados a partir de 2000 em revistas nacionais, internacionais e em sites de associações para rinite alérgia e asma. Para tanto, foram consultados os bancos de dados SciELO e Bireme, a partir das fontes Medline, Lilacs. Foram considerados na pesquisa dados sobre diagnóstico laboratorail tradicionais e inovadores. Os parâmetros de busca pesquisados no banco de dados PubMed foram: Allergic Rhinitis (\#1), Asthma (\#2), Treatment (\#3), Allergic Disease (\#4), Diagnosis (\#5). Os artigos encontrados através dessa estratégia foram revisados em duas ocasiões em série, para garantir a adequação da amostra. Uma estratégia similar foi executada no banco de dados SciELO, usando os mesmos parâmetros mencionados em Português. Foram incluídos os artigos que apresentaram em seu resumo ao menos a combinação de três dos termos \#1, \#2, \#3, \#4, \#5 estabelecidos. Ressalta-se que o tipo de asma focado nesta revisão é a asma alérgica, a qual apresenta metodologias compatíveis com as da rinite alérgica. 


\section{RESULTADOS E DISCUSSÃO}

Diferentes abordagens laboratoriais são utilizadas para o diagnóstico destas patologias. A confirmação do diagnóstico da rinite é feita inicialmente de forma clínica. A etiologia é de extrema relevância, pois além da confirmação do diagnóstico clínico a identificação dos agentes causadores é fundamental para direcionar o tratamento. As principais metodologias são: testes cutâneos, determinação de $\lg E \mathrm{e}$ teste de provocação nasal (SOLÉ et al., 2006).

O diagnóstico inicial da asma é realizado da mesma forma que a rinite alérgica, de forma clínica. Para o diagnóstico funcional o método mais utilizado é a espirometria. Outros testes complementares realizados no caso da espirometria apresentar um resultado normal são os testes de broncoprovocação, medidas de volume expiratório forçado no primeiro segundo (VEF1) e medidas seriadas do pico do fluxo expiratório (PFE) (SOCIEDADE BRASILEIRA DE PNEUMOLOGIA E TISIOLOGIA, 2004).

\subsection{AVALIAÇÃO CLÍNICA}

Para o diagnóstico da rinite alérgica o histórico do paciente é um dos pontos mais importantes a ser considerado. A forma como as informações são obtidas requerem cuidado devendo ser feitas perguntas médicas gerais relacionadas ao meio onde o paciente vive e trabalha. Desta forma um número maior de detalhes é observado, possibilitando que o fator desencadeante possa ser corretamente esclarecido. Por exemplo, o paciente dificilmente relaciona a causa da alergia com o animal de estimação. Alguns fatores de risco estão associados, tais como: histórico familiar, poluição do ar (ambiente) e fumo. Os sintomas comuns são a perda do olfato, dificuldades em dormir, gotejamento nasal e tosse crônica (A, 2006; BOUSQUET et al., 2001). Quando a avaliação clínica indica que o paciente realmente é portador da rinite alérgica, são realizados exames laboratoriais confirmatórios como os testes in vivo e in vitro. Entre os principais alérgenos se destacam: poeira, ácaros, pólen, alérgenos de cães e gatos, fungos, alimentos e látex.

O diagnóstico da asma também considera o histórico familiar além de outras variáveis como as doenças relacionadas à hipersensibilidade. Se a exposição a alérgenos ou poluentes desencadeia tosse, aperto no peito ou respiração ofegante ou ainda se exercícios desencadeiam respiração ofegante e tosse. Alguns dos sintomas clássicos são falta de ar recorrente, tosse principalmente a noite, chiado e aperto no peito (BOUSQUET, et al., 2000). O histórico médico deve ser considerado para que outras patologias não sejam erroneamente diagnosticadas. Por exemplo, diagnosticar com asma um paciente que na verdade apresenta displasia broncopulmonar devido a oxigênio terapia realizada no nascimento prematuro (GOLDSTEIN; HAMILTON, 2006). É recomendado que o diagnóstico seja feito de 
forma diferencial entre crianças de cinco anos ou menores e crianças mais velhas e adultos. Em crianças pequenas é comum encontrarmos respiração dificultosa e tosse sem que estas estejam relacionadas à asma. Nestes casos o diagnóstico pode ser realizado aplicando broncodilatadores ou glicocorticoides, a melhora de sintomas na presença do medicamento indica a presença da asma. A espirometria não é confiável nesta faixa etária (5 anos ou menores), enquanto que em crianças mais velhas e adultos é possível realizar a demonstração de obstrução de vias aéreas reversível e variável (BOUSQUET, et al., 2000). Este exame consiste na medição do volume máximo de ar inalado quando se utiliza a maior inspiração possível. É feita uma comparação entre os valores do paciente com os valores esperados. É o método mais indicado na confirmação do diagnóstico da asma, mas deve ser repetido para aumentar a sensibilidade do mesmo (KIM; MAZZA, 2011).

\subsection{ABORDAGEM LABORATORIAL}

\subsubsection{Hemograma}

Neste exame avaliam-se os eritrócitos, leucócitos e plaquetas. Sendo que, dentre os leucócitos há linfócitos, monócitos e granulócitos (eosinófilos, basófilos e neutrófilos). Para os processos alérgicos o parâmetro mais relevante é o da eosinofilia. Entretanto, o aumento destas células pode ter diversas causas como doenças do trato respiratório, do tecido conjuntivo, cutâneas, mieloproliferativas, endocrinológicas, gastrointestinais, imunodeficiência, neoplasias e infecções, não sendo restrito a doenças alérgicas. O início do processo da eosinofilia ocorre com o aumento da IL-3, do fator estimulador de colônias de granulócitos-macrófagos (GMCSF) e da IL-5. A IL-3 e o GM-CSF promovem a expansão de células, a IL-5 por sua vez é a citocina responsável pela diferenciação dos eosinófilos (MENDES et al., 2000).

A associação do hemograma que apresenta eosinofilia e obstrução das vias aéreas é um forte indicativo para o diagnóstico da asma (TAVARES, 2006). Já foi observada uma correlação direta entre a contagem de eosinófilos, a gravidade dos sintomas e a magnitude da hiper-reatividade bronquial. Outra análise para avaliar a eosinofilia é no escarro/saliva. Essa metodologia não invasiva indica a o aumento destas células especificamente nas vias aéreas, o que é um forte indicativo que paciente possui asma alérgica (SZEFLER et al., 2012). As vantagens deste método é que secundariamente aos processos patológicos há alterações sanguíneas, as quais podem ser visualizadas e monitoradas, o hemograma reflete o exato momento da coleta. As desvantagens é que o hemograma não faz o diagnóstico, mas é uma ferramenta muito importante. Como observado diversas patologias podem estar relacionadas as alterações eosinofílicas (MENDES et al., 2000). 


\subsubsection{Velocidade de hemossedimentação (VHS)}

A visualização da sedimentação dos eritrócitos é utilizada desde a os tempos da Grécia antiga. Em 1924, Alf Westergreen publicou uma técnica para visualizar a reação de sedimentação, técnica a qual sofreu pequenas alterações e em 1993 foi aceito como referência internacional. Os valores utilizados como referências devem ser obtidos a partir da população da região e fatores como sexo e idade. Uma velocidade diminuída pode estar associada à insuficiência cardíaca, hipoproteinimia, entre outros; enquanto que uma velocidade aumentada é correlacionada a estados infecciosos e inflamatórios (MARTINS et al., 2007; MARQUES FILHO, 2004). Dentre as vantagens da VHS destacamos a simplicidade do método, rapidez e baixo custo (MARQUES FILHO, 2004). A maior desvantagem é a falta de especificidade. Os resultados podem ser alterados dependendo do tempo para análise e a forma da coleta. Não existe, até o momento, uma referência brasileira para análise de comparação do resultado obtido (MARTINS et al., 2007).

\subsection{EXAMES DE ALTA COMPLEXIDADE}

\subsubsection{Determinação de leucotrienos}

A determinação é feita através do teste Cellular Antigen Stimulation Test (CAST). Nesta técnica os basófilos são expostos aos alérgenos de interesse. Se estes forem sensíveis liberarão sulfidoleucotrienos os quais são medidos por um teste de ELISA. Esta metodologia pode ser usado tanto para avaliar reações alérgicas mediadas por $\lg E$ como as não mediadas, o que representa sua maior vantagem; a principal desvantagem é o custo elevado não sendo portanto recomenda para avaliar sensibilidades mediadas por lgE (POTTER, 2006).

\subsubsection{Determinação de Triptase}

A triptase é um mediador pré-formado liberado pelo mastócito, quando a célula é ativada e pode ser detectado por até 6 horas após sua liberação. É utilizada em duas principais situações: para determinar se ocorreu anafilaxia e no diagnóstico de mastocitose (DAHER et al,. 2009). Um dos kits disponíveis é o ImmunoCAP® Triptase. O princípio do teste é um imunoensaio em sanduíche, a fase sólida possui anticorpos anti-triptase que entram em contato com a amostra do paciente. É feita uma lavagem e se adiciona anticorpos anti-triptase marcados com uma enzima, uma nova lavagem é realizada e o substrato da enzima é adicionado. A fluorescência 
resultante será proporcional a concentração de triptase (Thermo Fisher Scientific). A grande vantagem é que o teste auxilia na avaliação e identificação de anafilaxia, como nem toda reação anafilática gera aumento de triptase esta é a grande limitação do teste, representando sua desvantagem (WILLIAMS et al., 2008).

\subsection{EXAMES ESPECÍFICOS}

\subsubsection{Teste Percutâneo e Teste Intradérmico}

O teste cutâneo foi desenvolvido em 1865 por Blackley, um médico homeopata. A forma como é utilizado atualmente foi proposta por Lewis com pequenas modificações de Pepys em 1968 (MOTTA; KALIL; BARROS 2005). A reação alérgica apresentada neste teste, quando positivo, é mediada pela IgE. A resposta imediata é gerada pela degranulação dos mastócitos, se observa extravasamento do plasma e vasodilatação. $\mathrm{Na}$ fase tardia há uma variedade celular do infiltrado, células mononucleares, eosinófilos, basófilos e neutrófilos. Esta fase se desenvolve entre 3 a 5 horas, tem o seu pico entre 6-12 horas e desaparece em 24 horas. Algumas variáveis que devem ser cuidadosamente consideradas neste teste: quantidade do alérgeno injetado, grau de sensibilização, liberação e reatividade da pele aos mediadores dos mastócitos. Nos exames cutâneos além do procedimento para os alérgenos é necessário um controle positivo (histamina) e um controle negativo (conservante utilizado para o alérgeno). O objetivo é comparar as reações entre controles com as reais reações dos alérgenos (FERNÁNDEZ-BENÍTEZ, 2003). Dentre as técnicas utilizadas, o teste de puntura consiste na aplicação da substância em forma líquida na região do antebraço seguida por uma perfuração da pele. Previamente é necessário anti-sepsia da região e verificar se não existem lesões. Após 15 minutos se realiza a medição das pápulas e do controle negativo. Se for observado diâmetro igual ou maior que 3 milímitros $(\mathrm{mm})$ o resultado é positivo (MOTTA; KALIL; BARROS 2005). A avaliação da resposta dos testes pode ser feita através da medição utilizando uma régua milimetrada ou através de laser (FERNÁNDEZ-BENÍTEZ, 2003). Da mesma maneira que a técnica de puntura, a intradérmica necessita de anti-sepsia e a região utilizada também é o antebraço. $O$ que difere as técnicas é que a aplicação na intradérmica é feita com uma seringa. As pápulas com diâmetros maiores de $3 \mathrm{~mm}$ indicam positividade, só que neste teste o tempo da reação indica o tipo que está envolvido. Entre 15 a 30 minutos: reação do tipo I; de 4 a 8 horas: reação de Arthus e após 24 a 48 horas: reação do tipo IV (MOTTA; KALIL; BARROS, 2005).

Os testes cutâneos podem apresentar uma reação "falso-positiva", porque a presença da IgE não significa necessariamente que o paciente irá desenvolver a alergia. O desenvolvimento da alergia é um processo fisiológico complexo. Desta forma é necessário realizar uma correta correlação com o histórico e os achados dos exames. Deve-se considerar que os extratos utilizados afetam diretamente a resposta do teste, ou seja, concentrações baixas ou a potência dos mesmos podem 
resultar em falso-negativos ou falso-positivos (AAAI, 2006). Há algumas condições onde os testes cutâneos são afetados. Entre estas encontramos a relação direta com a idade do paciente (maior idade, menos sensível se torna o teste), maior pigmentação na pele pode tornar a medição mais complexa, algumas patologias e o uso de medicamentos também podem vir a reduzir a sensibilidade do teste. Por exemplo, pacientes com diabetes ou que façam uso de corticosteróides (AAAl, 2006). Dentre as vantagens do teste percutâneo destacamos o fato de ser economicamente mais acessível, seguro e de fácil execução (AAAl, 2006; MOTTA, KALIL; BARROS, 2005). Já o teste intradérmico apresenta melhor reprodutibilidade que 0 teste de puntura e alta sensibilidade (MOTTA; KALIL; BARROS, 2005). O exame é realizado quando o paciente apresenta resposta negativa para 0 teste percutâneo, porém sua história clínica indica a presença da alergia (AAAI, 2006). A desvantagem dos testes cutâneos é que não são recomendados a pacientes que utilizem beta-bloqueadores, porque ocorre um aumento considerável do risco de anafilaxia. Entretanto, recentemente Fung e Kim (2010) demonstraram que o teste é seguro. Foram acompanhados 191 pacientes que utilizavam beta-bloqueadores, dentre os quais 72 tiveram resultados positivos para o teste dérmico e nenhum deles apresentou qualquer problema.

\subsection{2 lgE testes (in vitro)}

A determinação de IgE pode ser feita de forma total ou específica. A IgE total é dosada através de metodologia imunoenzimática. Valores altos podem ser estar relacionados a diversos fatores ambientais e relativos a características do próprio paciente. A determinação de IgE é importante no diagnóstico diferencial na suspeita de esofagite eosinofílica, alergia ocupacional de causa não esclarecida, aspergilose pulmonar alérgica e sinusite alérgica por fungos, representando uma grande vantagem. Por outro lado, a presença da $\operatorname{lgE}$ não faz diagnóstico de doença alérgica, pode haver nível elevado de lgE total em pacientes não atópicos, sendo esta a desvantagem.

O ensaio conhecido como RAST (Radio Allergen Sorbent) foi o primeiro descrito utilizando a medida de Ac específicos contra antígenos (Ag). Utiliza a IgE específica como parâmetro no diagnóstico, pois esta indica a sensibilização (DAHER et al., 2009). No método original se utilizava Ac anti-IgE marcados radioativamente, o termo RAST permaneceu para os ensaios atuais mesmo com a modificação de não se utilizar mais radioisótopos (SOUZA, 2011). A dosagem de IgE específica apresenta seus resultados de forma quantitativa em $\mathrm{KU} / \mathrm{L}$ sendo inferior a 0,35 indetectável e acima de 17,5 considerado muito forte. Este teste pode ser feito utilizando pool de alérgenos. Neste caso, há uma mistura de alérgenos de forma a otimizar o ensaio, considerando que, no caso do paciente apresentar resultado negativo não será preciso realizar diferentes testes (DAHER et al., 2009). É uma alternativa indicada para pacientes que utilizam medicamentos que podem interferir no método in vivo ou que estão sob condições em que este teste não pode ser realizado (presença de eczema, dermografismo, pós-anafilaxia ou risco de reações 
sistêmicas) (DAHER et al., 2009). A desvantagem é o custo maior se comparado com os testes cutâneos, tempo de execução e para alguns alérgenos pode ter a sensibilidade reduzida comparada com o teste cutâneo (GOLDSTEIN; HAMILTON, 2006). Outra situação relacionada aos testes de $\lg E$ é que estes medem a $\lg E$ presente no soro, ou seja, pode não refletir exatamente a IgE fixada nos tecidos (CHINOY,YEE; BAHNA, 2005). Entre os principais sistemas utilizados pelos laboratórios comerciais encontramos o Immulite ${ }^{\circledR}$ (Siemens), IgE Total e o ImmunoCAP® (ANTI-IGE), IgE específico (SILES; HSIEH 2011). O Immulite® é composto por instrumento e software, realizando imunoensaio quimioluminescente. O sistema é automatizado e segue os seguintes passos: adição da amostra e do reagente à fase sólida; seguido por: incubação, lavagem, adição de reagente ácido e básico (MACCHIAVERNI, 2008). O substrato adamantildioxetano fosfato gera um intermediário instável que ao quebrar produz luz a qual é proporcional ao analito e será detectado pelo tubo fotomultiplicador (PMT). A concentração final é dada em UI/L e a leitura mínima detectável é de 1,5 UI/L.

O ImmunoCAP® possui um formato de micro-arranjos, no qual há um substrato sólido onde estão os componentes alérgenos ordenados em triplicata na vertical. A detecção da presença de Ac $\operatorname{lgE}$ do paciente é feita através da fluorescência de um Ac secundário anti-humano. Os resultados são obtidos através da análise do software Microarray Image Analysis Software - MIA, que apresenta resultados semi-quantitativos na unidade ISU, dividido em quatro níveis: 0 (zero) não detectável e três (3) muito elevado (Phadia). Como vantagens o Immulite® por ter o sinal amplificado leva a uma detecção de limites mais baixos e apresenta maior sensibilidade que os imunoensaios enzimáticos (ELISA) (MENEZES, 2009). Enquanto o ImmunoCAP® utiliza a tecnologia de micro-arranjos o que permite um maior número de alérgenos sejam testados e um único ensaio. Em relação às desvantagens, o Immulite ${ }^{\circledR}$ necessita de equipamentos específicos para sua leitura com limnômetro e fotomultiplicadores (MENEZES, 2009) e o ImmunoCAP® em relação a alergia alimentar, os anticorpos $\lg E$ circulantes podem permanecer não detectáveis apesar do histórico clínico convincente, porque estes Ac podem ser dirigidos aos alérgenos revelados ou alterados durante o tratamento industrial, a confecção ou digestão e, por isso, não existem nos alimentos originais para os quais o doente é testado. Os resultados da classe zero (0) para venenos indicam ausência ou níveis de Ac IgE circulantes específicos do veneno não detectáveis. Estes resultados não excluem a existência de hipersensibilidade clínica atual ou futura à picada do inseto (Phadia).

\subsubsection{Teste de Provocação}

É utilizado em situações onde não se consegue encontrar o agente causador da alergia, ou ainda quando os outros testes (in vitro/ in vivo) apresentam resultados diferentes entre si (FERNÁNDEZ-BENÍTEZ, 2003). Os dois testes mais utilizados são o de provocação com metacolina e por exercício, ambos são de dose-resposta (CRAPO et al., 2000). 
Nos testes de broncoprovocação, mede-se a reatividade das vias aéreas, que ao se expor a determinados estímulos pode ter um aumento do tônus. Entre os diferentes métodos usados, o mais aplicado realiza diferentes medidas do Volume Expiratório Forçado no Primeiro Segundo (VEF1). Essas medidas são feitas entre as administrações de diferentes concentrações por aerossol de agentes farmacológicos com efeitos contráteis na musculatura lisa. Há duas formas de expressar o resultado, a primeira como dose cumulativa e a segunda como concentração do agente que produziu a queda de $20 \%$ no VEF1 (LOPES; JANSEN, 2008). A metacolina é uma droga que leva ao estreitamento temporário das vias aéreas, no teste de provocação é dada uma dose dessa droga, caso se observe a diferença entre o VEF1 inicial maior que $20 \%$, há a indicação de resultado positivo (ALI, 2011).

Nos casos onde há suspeita de asma induzida por exercício é realizado o teste de broncoprovocação com exercício. Esse se diferencia do anterior por não haver exposição a nenhum agente. O exercício é realizado pelo período de 6 a 8 minutos e se observa o VEF1 a cada 5 minutos, essa medida é repetida por seis vezes, se for observada diferença de $10-15 \%$ do VEF1 basal o diagnóstico é positivo (LOPES \& JANSEN, 2008). O teste de provocação com metacolina pode ser usado para determinar o risco de desenvolver asma, sendo a principal vantagem; mas não pode ser aplicado em pacientes que apresentem limitação severa das vias aéreas, que tiveram ataque cardíaco nos últimos meses, hipertensão incontrolada ou aneurisma aórtico (CRAPO et al., 2000).

\section{COMPARAÇÃO ENTRE OS EXAMES}

Teste Percutâneo versus Intradérmico: o teste percutâneo apresenta uma especifidade maior, porém o intradérmico apresenta uma maior sensibilidade (GOLDSTEIN; HAMILTON, 2006). Uma desvantagem que foi ressaltada por diversos pesquisadores, entre eles o grupo de Forte et al., (2001) é que a idade é pode influenciar no teste cutâneo. Os resultados obtidos demonstraram a positividade frente a testes cutâneos para determinados alérgenos significativos a partir dos 12 meses de idade e para outros somente a partir dos 4 anos. Tais dados possuem duas justificativas: a primeira seria pela imaturidade do sistema imune e a segunda pela menor exposição aos alérgeno ao longo da vida (FORTE et al., 2001).

Teste Intradérmico versus IgE específica: diversos estudos abordando o imunoensaio com anticorpos IgE específicos questionam sobre sua especificidade e sensibilidade em relação ao teste intradérmico. Yunginger et al., (2000) conclui que esses dois tipos de testes não são intercambiáveis, cada um apresenta suas vantagens e desvantagens e dependem de diversas variáveis que incluem: situação do paciente, treinamento do próprio aplicador (no caso do teste de punção dérmica) entre outros fatores.

Chinoy, Yee e Bahna (2005) no estudo de comparação entre a técnica percutânea e a de RAST para alérgenos comuns a ambientes residenciais (ácaro, epitélio de cão e gato), apresentou uma maior positividade no teste intradérmico. 
Provavelmente a diferença de sensibilidade deve ser provocada pela diferença entre as bases imunológicas dos métodos.

Teste Cutâneo versus lgE Total versus Eosinofilia versus Diagnóstico clínico da rinite alérgica. Manica et al., (2004) realizou um estudo com 165 pacientes durante 0 período de dois anos. $O$ objetivo foi comparar a positividade entre 0 diagnóstico clínico e os exames laboratoriais. Para o diagnóstico clínico se utilizou o escore de sinais e sintomas (ESS), nos testes cutâneos o resultado foi considerado positivo em pápula com diâmetro maior ou igual a $3 \mathrm{~mm}$, a dosagem de IgE total foi feita por eletroquimioluminescência e a medida de eosinófilos foi feita por citometria de fluxo. Foi detectado uma baixa prevalência nos testes cutâneos e baixa correlação com o ESS, enquanto a IgE específica apresentou boa correlação com os testes cutâneos e com a lgE total. O grupo conclui questionando que a acurácia dos testes podem resultar em diagnósticos equivocados.

\section{NOVOS TESTES PARA DIAGNÓSTICO DA ASMA E/OU RINITE}

\subsection{C3 E C4 COMO BIOMARCADORES DA ASMA}

C3 e C4 são proteínas constituintes do sistema complemento, o qual é um complexo sistema multiproteico, considerado um dos mecanismos mais importantes da resposta imune inata. Mosca et al., (2011) analisaram os exames de 70 crianças, sendo que 40 eram portadoras de asma intermitente e 30 saudáveis (livre de asma), comparando os valores dos níveis séricos de $\mathrm{C} 3$ e C4. Foi observado um aumento significativo nos níveis de $\mathrm{C} 3$ e de $\mathrm{C} 4$ das crianças portadores de asma intermitente, sugerindo o possível uso dessas proteínas como biomarcadores.

\subsection{LEUCOTRIENO E4 NA URINA}

O leucotrieno E4 é originado a partir da atividade de células que participam da inflamação alérgica. A dosagem deste seria uma forma indireta de medir a atividade cisteinil leucotrieno nos pulmões. A concentração está aumentada em pacientes com crises de asma, expostos a alérgeno ou em pacientes que utilizaram aspirina. É recomendada para esta medição a espectrometria de massa (SZEFLER et al., 2012). 


\subsection{EXPRESSÃO DA LUCIFERASE INDUZIDA POR LIGAÇÃO DA IGE}

$O$ receptor de Ig possui quatro subunidades: $\alpha, \beta$ e duas subunidades $\gamma$. Entretanto, apenas a a tem habilidade de se ligar a lgE. O grupo de Nakamura et al., (2010) buscando uma forma de detectar a IgE humana, transfectou roedores com o gene da subunidade $\alpha$ ou ainda com os genes de todas subunidades. $O$ intuito foi utilizar estas células para a análise do soro de pacientes. Na metodologia as células foram sensibilizadas com o soro dos pacientes, depois expostas aos agentes que levariam a degranulação.

\section{CONSIDERAÇÕES FINAIS}

Os exames laboratoriais são fundamentais para 0 diagnóstico e acompanhamento da doença possibilitando a análise do tratamento e se está adequado ao paciente. $\mathrm{O}$ que se observa nas metodologias discutidas no presente artigo é que cada uma apresenta suas vantagens e desvantagens. Numa rápida comparação vemos que exames de rotina como hemograma e VHS apresentam baixo custo, porém não possuem especificidade, indicando alterações relacionadas à alergia o que não a comprova e nem indica qual o agente causador. Outros exames como a quimiluminescência e a determinação de leucotrienos apresentam como desvantagem o custo. Observando o número de pacientes que necessitam destes exames, a utilização dos mesmos na rotina geraria um grande impacto para o sistema público de saúde. A determinação de triptase é de uso restrito, sendo mais específica para o caso de avaliação de reação anafilática; enquanto os testes de provocação bronquial avaliam somente a asma, não incluindo necessariamente a alergia. Os testes dérmicos apresentam diversas vantagens como custo e boa sensibilidade, entretanto entre suas desvantagens temos a necessidade de um profissional capacitado para avaliar os resultados que dependendo da forma como $o$ teste é feito sofre variações, além de influências que incluem: sexo, idade e uso ou não de medicamentos. A análise de lgE in vitro tem como desvantagem usar como material o soro, assim não representa necessariamente a IgE do tecido, porém uma vantagem é que pode ser aplicada a pacientes que não podem se submeter aos testes dérmicos (MENEZES, 2009; WILLIAMS et al., 2008; GOLDSTEIN; HAMILTON, 2006; POTTER, 2006; MOTTA, KALIL; BARROS 2005).

O que esperar para um futuro próximo? A melhor compreensão da fisiopatologia da asma e da rinite, resultante de um número cada vez maior de estudos realizados por diversos pesquisadores nos permitirá saber exatamente o mecanismo de como cada célula, receptor e citocinas estão envolvidos. Este conhecimento, por sua vez, levará ao desenvolvimento de novas metodologias cada vez mais sensíveis e específicas que irão medir esses "marcadores" indicando a presença ou não da alergia, se o tratamento está respondendo satisfatoriamente ou se o paciente tem potencial para desenvolver a alergia. Devemos considerar a evolução da tecnologia que permitirá realizar testes com mais automação e 
padronização, diminuindo a manipulação humana e aumentando a acurácia dos mesmos.

\section{REFERÊNCIAS}

ALI, Zarqa. How to Diagnose Exercise Induced Asthma?. Asian Journal Sports Medicine, v. 2, n. 2, p. 63, 2011.

ANTI-IGE, ImmunoCAP Total IgE; CONJUGATE, ImmunoCAP Total IgE. ImmunoCAP® IgE. Disponível em <http://www.phadia.com/Global/Corporate \%20Allergy/Files/DfU/Assay\%20Kit\%20lgE/DfU-ImmunoCAP-ISAC-20-01-02-3PT.pdf> Acesso em: 24 nov 2014.

BOSTANTZOGLOU, Clementine et al. Clinical asthma phenotypes in the real world: opportunities and challenges. Breathe, v. 11, n. 3, p. 186, 2015.

BOUSQUET, J. et al. Allergic rhinitis and its impact on asthma. ARIA. In collaboration with the World Health Organization. J Allergy Clin Immunol, v. 108, n. S147, 2001.

BOUSQUET, J. et al. Global initiative for asthma (GINA) and its objectives. Clinical and Experimental Allergy, v. 30, n. 6; SUPP/1, p. 2-5, 2000.

CANONICA, G. W; COMPALATI, E. Minimal persistent inflammation in allergic rhinitis: implications for current treatment strategies. Clin \& Experimental Immunol, v. 158 , n. 3, p. 260-271, 2009.

CASAGRANDE, Rejane RD et al. Prevalência de asma e fatores de risco em escolares da cidade de São Paulo. Rev Saúde Pública, v. 42, n. 3, p.517-523, 2008.

CHINOY, Birjis; YEE, Edgar.; BAHNA, Sami L. Skin testing versus radioallergosorbent testing for indoor allergens. Clin Mol Allergy, v. 3, n. 1, p. 4, 2005.

CORDEIRO, Nelson Guilherme; SILVA, Eduardo Costa. Terapia Anti-IgE em Alergia Respiratória. Rev Hospital Universitário Pedro Ernesto, v. 7, n. 2, 2008.

CRAPO, R. O. et al. Guidelines for Methacholine and Exercise Challenge Testing 1999. This official statement of the American Thoracic Society was adopted by the ATS Board of Directors. July 1999. Am J Resp Critical Care Med. v.161, n. 1, p. 309-329, 2000.

DAHER, Silvia et al. Diagnóstico em Doenças Alérgicas Mediadas por IgE. Rev Bras Alerg Imunopatol. v.32, n. 1, p. 1-8, 2009.

DE SOUZA, Flávia Rabelo Frayha. Avaliação do teste de contato atópico na alergia ao leite de vaca IgE mediada e nas doenças eosinofílicas do trato digestório. 2011. Tese de Doutorado. Universidade de São Paulo. 
FERNÁNDEZ-BENÍTEZ M. Métodos diagnósticos en alergia. Técnicas in vivo e in vitro. Protocolos diagnósticos y terapéuticos en Pediatria, v. 1, p.153-167, 2003.

FORTE, Wilma Carvalho Neves et al. Testes cutâneos de hipersensibilidade imediata com o evoluir da idade. J Pediatria, v. 77, n. 2, p. 112-118, 2001.

FUNG, Irene N.; KIM, Harold L. Skin prick testing in patients using beta-blockers: a retrospective analysis. Allergy Asthma \& Clin Immunol, v. 6, n. 1, p. 2-4, 2010.

GOLDSTEIN, M.D.; HAMILTON, Robert G. AAAAI Work Group Report: Allergy Diagnosis in Clinical Practice. 2006.

HAMILTON, Robert G. et al. IgE antibody-specific activity in human allergic disease. Imunnol Research. v. 47, n. 1-3, p. 273-284, 2010.

HOLANDA, Márcia Alcântara. Asmáticos brasileiros: o tratamento desejado. J Pneumol, v. 26, n. 3, 2000.

HUSSEIN, Y et al. Interleukin 13 Receptors as Biochemical markers in atopic patients. J Investig Allergol Clin Immunol v.21, n. 2, p.101-107, 2010.

KIM, H.; MAZZA, J. Asthma. Allergy, Asthma Clin Immunol. v. 7, p.1-9, 2011.

LEAL, Renata Cristina de Angelo Calsaverini, et al. Modelo assistencial para pacientes com asma na atenção primária. Rev Assoc Med Bras. v.57, n.6, p. 697701. 2011.

LOPES, Agnaldo José; JANSEN, José Manoel. Diagnóstico e acompanhamento funcional da asma brônquica. Rev Hosp Univ Pedro Ernesto. v.7, n. 2, p.58-61, 2008.

MACCHIAVERNI, Patrícia. Caracterização quantitativa da transferência de anticorpos anti- Dermatophagoides pteronyssinus via placenta e colostro materno. 2008. Tese de Doutorado. Universidade de São Paulo.

MACEDO, Luciana Bilitário; ARAÚJO, Camila Biscaia Silva; DIAS, Cristiane Maria Carvalho Costa. Efeitos dos programas educacionais em pacientes com asma: revisão sistemática. ASSOBRAFIR Ciência, v. 3, n. 2, p. 43-52, 2012.

MANICA, Denise et al. Teste cutâneo de leitura imediata em um serviço terciário do sul do brasil: relação com diagnóstico clínico e gravidade da rinite alérgica. Rev

Bras Alerg Imunopatol, v. 31, n. 4, p. 151-157, 2004.

MARQUES FILHO, Jojé. Velocidade de hemossedimentação de segunda hora: qual a sua utilidade?. Rev Assoc Med Bras. v.50, n. 2, p. 114-115, 2004.

MARTINS, Giuliano S., et al. Agregação e sedimentação eritrocitária utilizando VHS (velocidade de hemossedimentação) e espectrofotometria UV-Vis. Rev Matéria. v.12, n. 1, p.206-214, 2007.

MENDES, D. M. et al. Eosinophilia. Rev Bras Alerg Imunol., v.23, n.2, 2000. 
MENEZES, C. J. S. Importância do Diagnóstico Sorológico de Toxoplasmose. 2009. 54f. Monografia (Especialização em Análises Clínicas). Faculdades Integradas de Jacarepaguá, Brasília, 2009.

MOSCA, Tainá, et al. Componentes C3 e C4 do sistema complemento como biomarcadores no diagnóstico de asma atópica intermitente. J Pediatria, v.87, n. 6, p. 512-516, 2011.

MOTTA, Antônio Abílio; KALIL, Jorge; BARROS, Myrthes Toledo. Testes cutâneos. Rev Bras Alerg Imunopatol, v. 28, p. 73-83, 2005.

NAKAMURA, R. et al. A convenient and sensitive allergy test: IgE crosslinkinginduced luciferase expression in cultured mast cells. Allergy, v. 65, n. 10, p. 12661273, 2010.

NATHAN, Robert A. Management of Patients with Allergic Rhinitis and Asthma \& colon; Literature Review. Management. v.102, n. 9, p.935 - 941, 2009.

NG, Chew Lip; WANG, D. Y. latest developments in allergic rhinitis in allergy for clinicians and researchers. Allergy, v. 70, n. 12, p. 1521-1530, 2015.

NUNES, Inês Cristina Camelo. Hipótese da Higiene: persistir é preciso!. Rev Bras Alerg Imunopatol, v. 34, n. 2, 2011.

PAHO, Pan American Health Organization. Doenças respiratórias crônicas. Disponível em: http://www.paho.org/bra/index.php?option= com_content\&view=article\&id=581:doencas-respiratorias-cronicas\&ltemid=539. Acesso em: $01 \mathrm{dez} 2015$.

POTTER, P. C. Clinical Indications and Interpretation of the Cast. Curr Allergy \& Clin Immunol, v. 19, n. 1, p. 14-17, 2006.

SARINHO, Emanuel; CRUZ, Álvaro Antônio. Anticorpo monoclonal anti-lgE no tratamento da asma e de outras manifestações relacionadas a doença alérgica. $\mathbf{J}$ Ped, v. 82, n. 5, p. 127-132, 2006.

Siemens Medical Solutions Diagnostics IMMULITE® 2000/2500 Operators. New Jersey, USA. Document Number: 600849-0001. Revision A, Version 5.xx. Feb 2007. Disponível em: < http://sky2.ch/Doc/l2500.pdf> Acesso em: 24 nov. 2014.

SILES, Roxana I.; HSIEH, Fred H. Allergy blood testing: A practical guide for clinicians. Clevel Clin J Med. v. 78, n. 9, p. 585-592, 2011.

SOLÉ, Dirceu et al. II Consenso Brasileiro Sobre Rinites 2006. Rev Bras Alerg Imunopatol. v. 29, n. 1, p. 29-58, 2006.

SOLÉ, Dirceu; CAMELO-NUNES, Inês C. A dimensão do problema da asma e da rinite alérgica no brasil: prevalência, hospitalizações e mortalidade. Gaz Med Bahia, v.78, n. 2, p. 3-10, 2008. 
SZEFLER Stanley J. et al. Asthma outcomes: Biomarkers. J Aller Cli Immunol, v. 129, n. 3, p. S9-S23, 2012.

TAVARES, Beatriz. Exames complementares no diagnóstico da asma grave. Rev Bras Alerg Imunopatol, v. 29, p. 117-122, 2006.

Thermo Fisher Scientific Laboratórios <https://www.thermofisher.com/en/home.html> Acesso em: 22 nov. 2014.

TOWNLEY, Robert G.; SAPKOTA, Muna; SAPKOTA, Kiran. IL-13 and its Genetic Variants: Effect on Current Asthma Treatments. Disc Med, v. 12, n. 67, p. 513-523, 2011.

WILLIAMS P et al. Clinical Immunology Review Series: an approach to the use of the immunology laboratory in the diagnosis of clinical allergy. Clin Exp Immunol, v. 153, n. 1, p. 10-18, 2008.

YUNGINGER, John W. et al. Quantitative IgE antibody assays in allergic diseases. J Allergy Clin Immunol, v. 105, n. 6, p. 1077-1084, 2000.

ZAVADNIAK, Aleksandro F.; ROSÁRIO Nelson. Regulação da síntese de lgE. Rev Bras Alerg Imunopatol, v. 28, n. 2, p. 65-72, 2005.

Artigo recebido em: 05/08/2015

Artigo aprovado em: 26/01/2016 